\title{
LETTERS
}

\section{Eliminating racism in research}

Racism has no place in research. The proposed establishment of an Institute of Racism and Health to develop Canada's research capacity to assess and eliminate race-based inequalities in health may be useful as a long-term approach to coordinating and harnessing the wisdom that exists and best practices being developed. ${ }^{1}$ However, dismantling something as pervasive as racism requires an immediate, multipronged approach that does not rely on top-down knowledge-sharing.

All those engaged in the research ecosystem - funders, researchers, Research Ethics Boards - have an immediate role to play in eliminating racism. Right now, we can take an honest look at whose voices and perspectives are included in research funding prioritization. Right now, researchers identifying as Black, Indigenous people, or people of colour should have the opportunity to co-lead the process of dismantling racism throughout the research ecosystem. Right now, Research Ethics Boards can begin to think critically about how race is used in study protocols to minimize racebased harm and be intentional about including members of racialized groups in meaningful, nontokenistic ways to reinforce Institute-level priorities from the ground up. And right now, we can educate ourselves about the history of racism within research and its lasting impact.

So, yes, let's name the problem of racism, and approach it on a national scale. Additionally, let us commit to nonperformative allyship.

\section{Sharon Smile MBBS DM (Paeds)}

Developmental pediatrician, Holland Bloorview Kids Rehabilitation Hospital, Toronto, Ont.

\section{Alison Williams PhD}

Chair, Research Ethics Board, Holland Bloorview Kids Rehabilitation Hospital, Toronto, Ont.

Cite as: CMAJ 2021 April 6;193:E489. doi: 10.1503/cmaj.78230

\section{Reference}

1. Datta G, Siddiqi A, Lofters A. Transforming racebased health research in Canada. CMAJ 2021; 193:E99-100.

Competing interests: None declared.

Content licence: This is an Open Access article distributed in accordance with the terms of the Creative Commons Attribution (CC BY-NC-ND 4.0) licence, which permits use, distribution and reproduction in any medium, provided that the original publication is properly cited, the use is noncommercial (i.e., research or educational use), and no modifications or adaptations are made. See: https://creativecommons. org/licenses/by-nc-nd/4.0/ 